Article

\title{
An Innovative Bidirectional DC-AC Converter to Improve Power Quality in a Grid-Connected Microgrid
}

\author{
Sébastien Bissey, Sébastien Jacques *, Cédric Reymond and Jean-Charles Le Bunetel \\ Research Group on Materials, Microelectronics, Acoustics, and Nanotechnology, University of Tours, 37000 \\ Tours, France; sebastien.bissey@univ-tours.fr (S.B.), cedric.reymond@st.com (C.R.), lebunetel@univ-tours.fr \\ (J.-C.L.B.) \\ * Correspondence: sebastien.jacques@univ-tours.fr; Tel.: +33-760-407-142
}

\begin{abstract}
The management of the electrical energy still raises a huge interest for end-users at the household level. Home electricity management systems (HEMS) have recently emerged both to warrant uninterruptible power and high power quality, and to decrease the cost of electricity consumption, by either shifting it in off peak time or smoothing it. Such a HEMS requires a bidirectional DC-AC converter, specifically when an energy transfer is required between a storage system and the AC-grid, and vice versa. This article points out the relevance of an innovative topology based on sinusoidal waveforms from the generation of sine half-waves. Such a topology is based on a DC-DC stage equivalent to an adjustable output voltage source and a DC-AC stage (H-bridge) which are in series. The results of a complete experimental procedure prove the feasibility to improve the power quality of the output signals in terms of total harmonic distortion (THD-values about 5\%). The complexity of the proposed converter is minimized in comparison with multilevel topologies. Finally, wide band-gap semiconductor devices (SiC MOSFETs) are helpful both to warrant the compactness and the high efficiency (about 96\%) of the bidirectional converter, whatever its operation mode (inverter or rectifier mode).
\end{abstract}

Keywords: smart home electricity management system; bidirectional DC-AC converter; high power quality; high efficiency.

\section{Introduction}

The effective management of electricity still fulfills an important role in achieving the objectives of the sustainable development strategy, particularly addressed by the European Union's energy policy [1,2]. Distribution systems require two key performance indicators: efficient delivery, and reliability of service [3]. Their monitoring and controllability have been enhanced with the ongoing smart grid development [4]. In particular, the modern smart grid is intended to facilitate load-shifting, to avoid load peaks, and to identify automatically faults or outages [5]. All these issues are of utmost importance because of the huge increase of independent small scale power generation systems, also called microgrids. A microgrid, which must supply power to the electricity consumers, can mainly operate in two modes: grid-connected mode, and off-grid mode [6]. The off-grid mode can be achieved in two ways. The first one considers that the electrical power is not available, for example because of a failure or shutdown of the grid. The second one assumes that the power grid is totally inaccessible (i.e., islanded mode). Over several years, standalone microgrids have been widely discussed in the literature. In particular, these kinds of systems consist of photovoltaic (PV) arrays and/or wind turbines, and energy storage systems (i.e., flywheels, supercapacitors or batteries) both to design voltage regulation policy, and control-based load tracking systems $[7,8]$.

At the moment, power management strategies play an increasingly important role in power quality regulation for micro-grids [9]. In particular, the ultimate challenge is to control power flows 
to meet various operational objectives (e.g., cost minimization, guaranteed delivery, or security) by adjusting the power flow from or to the main grid, the distribution of energy resources, and the loads' controllability. In individual housing, this kind of strategy, also called home electricity management system (HEMS), can typically be implemented, for example, to promote the integration of renewable energies, and protect the electricity distribution system of a possible power outage [10].

Figure 1 shows an example of HEMS that has been recently discussed in the literature [11]. This kind of strategy achieves the following three main objectives:

- Uninterruptible power.

- High power quality.

- Management of the cost of electricity consumption, by either shifting it in off peak time or smoothing it (see Figure 2) [12].

Such a HEMS requires the implementation of a storage system. As a consequence, the AC loads can be supplied in two ways i.e., either from the AC grid or from an inverter in the situation where the storage system relieves the AC grid. These two operating modes can be controlled with a bidirectional DC-AC converter [13]. To improve the stability of the AC grid, this converter must be designed considering the following key elements: high efficiency and reliability, low total harmonic distortion (THD), and current control and voltage adaptation.

The use of a power converter in a microgrid can significantly increase voltage and current harmonics. These ones can provide resonances that can lead to the instability of the whole system $[14,15]$. Moreover, the control strategy of the power devices inside the converter has an impact on the power quality of a microgrid [16]. Multi-level inverters were introduced as early as the 1980s [17]. The role of a multi-level inverter is to vary the output voltage step by step through levels. A significant increase of the number of levels leads to a signal waveform comparable to a sine curve [18]. Thus, it helps to improve the power quality of the converter and, a fortiori, the microgrid. There are two ways to increase the number of levels: on the input side, increase the number of DC voltage sources, and multiply the number of power switches [19-21].

Multilevel inverter topologies are classified into two main categories:

- Single DC-source inverters. Examples of converters within this category are neutral-point-clamped (NPC) multilevel inverters introduced in 1981, and flying capacitor (FC) multilevel inverters emerged in 1992 [22].

- Multi DC-source inverters. One of the most popular topologies is the cascaded H-bridge (CHB) multilevel inverter. Multi DC-source inverters can also be classified into symmetrical (i.e., each DC provides the same voltage), and asymmetrical (i.e., DC source does not provide the same voltage) topologies. In comparison with symmetrical topologies, asymmetrical ones require less power switches, power diodes and drivers.

This manuscript proposes to demonstrate the relevance of a bidirectional DC-AC converter that has been very underdeveloped in the literature [23,24]. The proposed inverter is composed of two stages: a DC-DC one, and a DC-AC one. The manuscript proposes the following main contributions:

1. Enhance the literature review in the field of bidirectional DC-AC converters dedicated to microgrids.

2. Design and test a bidirectional DC-AC converter used in HEMS that have the following main features: high efficiency (higher than 95\%), high power quality (THD of the output signal lower than $5 \%$ ), and high compactness through the use of wide band gap ( $\mathrm{SiC}$ ) power devices.

This manuscript is composed of three main sections. In section 2, a complete literature review is proposed to highlight the limitations of existing DC-AC converters. In section 3, an innovative topology of a bidirectional DC-AC converter with the main characteristics previously quoted is introduced. Section 4 discusses the main experimental results, and proves the relevance of such a topology. 


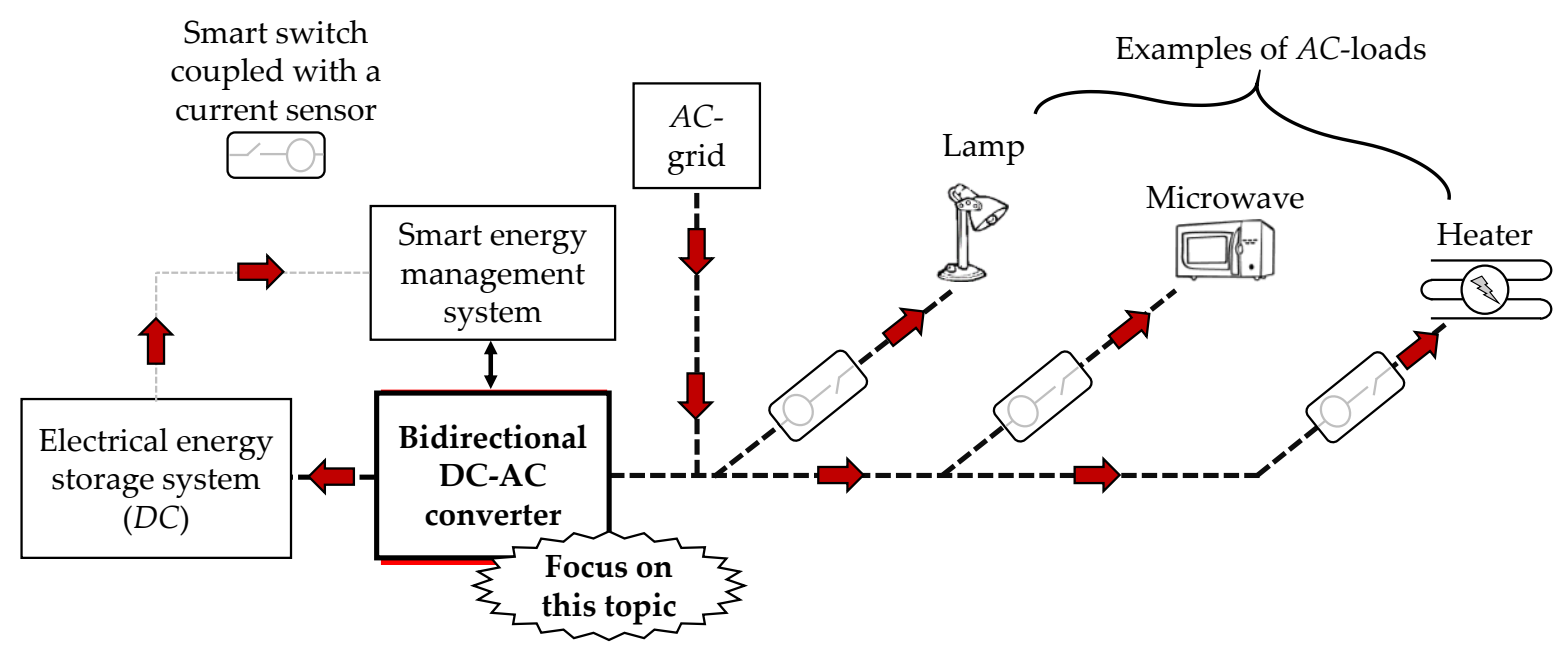

(a)

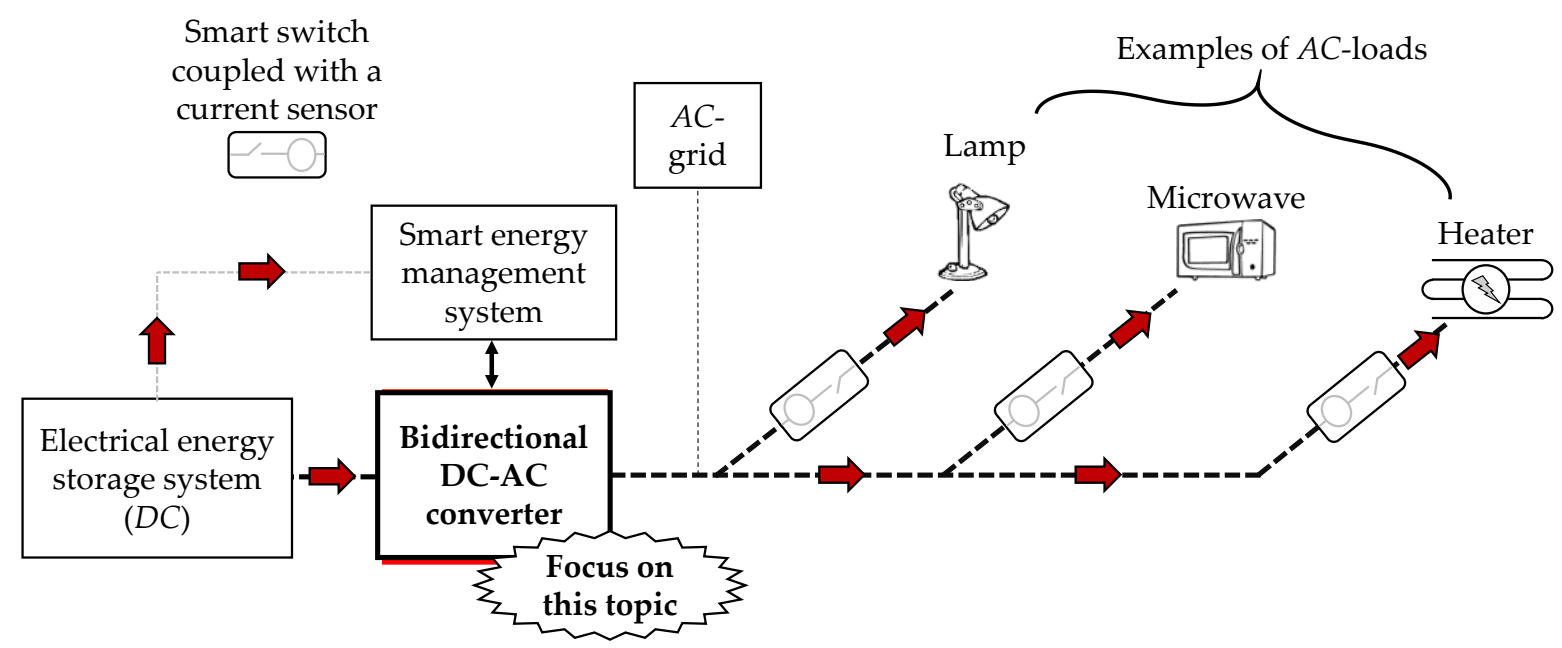

(b)

Figure 1. Example of a smart HEMS. (a) AC loads supplied by the AC grid; (b) AC loads supplied by an inverter in the situation where the storage system relieves the AC grid [11].

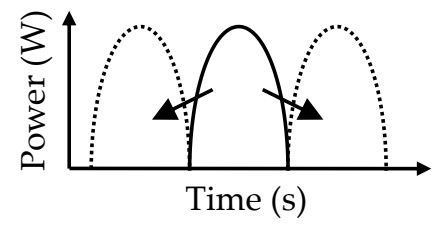

Load demand shifting (use of the storage system)

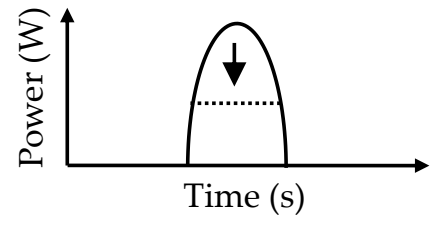

Load demand smoothing (use of smart plugs)

Figure 2. Example of a smart HEMS. (a) AC loads supplied by the AC grid; (b) AC loads supplied by an inverter in the situation where the storage system relieves the AC grid [11]. 


\section{Limitations of Existing DC-AC Topologies}

Multilevel converter topologies are still widely used for medium and high voltage applications, such as electrical motor drive or grid connected converters, because they generate very low harmonics. The higher the number of levels, the lower the harmonics. Multilevel converters can be divided into two categories: symmetric topologies, and asymmetric ones. Karimi et al. have recently pointed out that the performances of each category depend on the number of DC sources, and the number of semiconductor devices that must be controlled [25].

The voltage of the DC sources determines the maximum amplitude of the output voltage. The number of DC sources sets the number of voltage levels. As can be seen in Figure 3, it is possible to design a multilevel inverter with approximately the same number of DC sources up to 7 levels. Above this limit asymmetric topologies offer the possibility to use fewer DC sources.

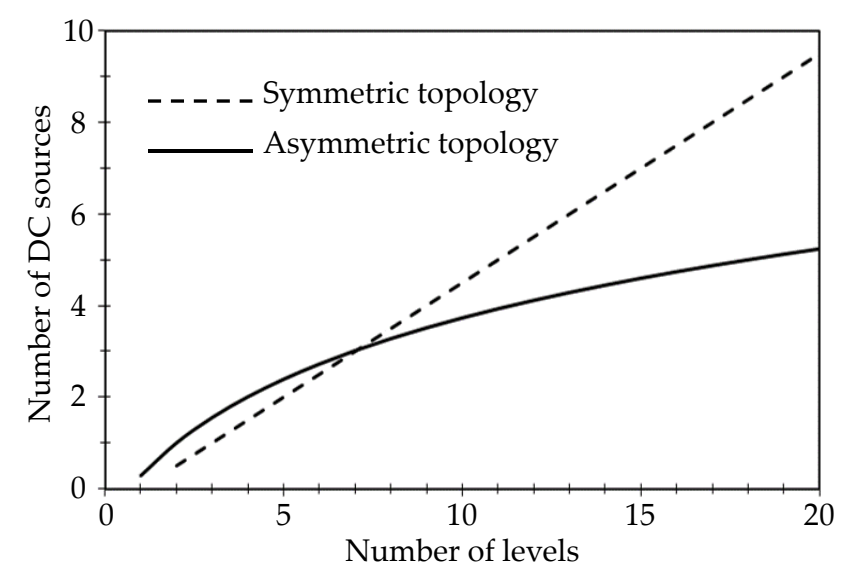

Figure 3. Symmetric and asymmetric multilevel inverters: variation of the number of DC sources versus the number of levels [25].

Multilevel converters may also require a high number of power semiconductor devices to be controlled, gate drivers, and diodes. As can be seen in Figure 4, asymmetric structures meet their absolute meaning when the number of levels is higher than seven. Thus, it helps to reduce the number of gate drivers, and the complexity of the control strategy.

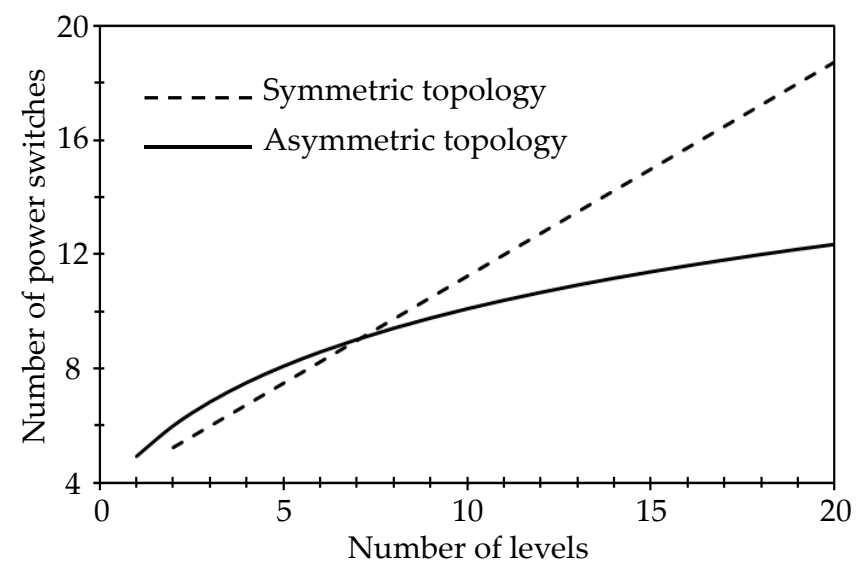

Figure 4. Symmetric and asymmetric multilevel inverters: variation of the number of power switches versus the number of levels [25]. 
At the moment, neutral-point clamped (NPC), flying capacitor (FC) also known as capacitor clamped, and cascaded H-bridge $(\mathrm{CHB})$ multilevel converters are the most developed topologies (see Figure 5).

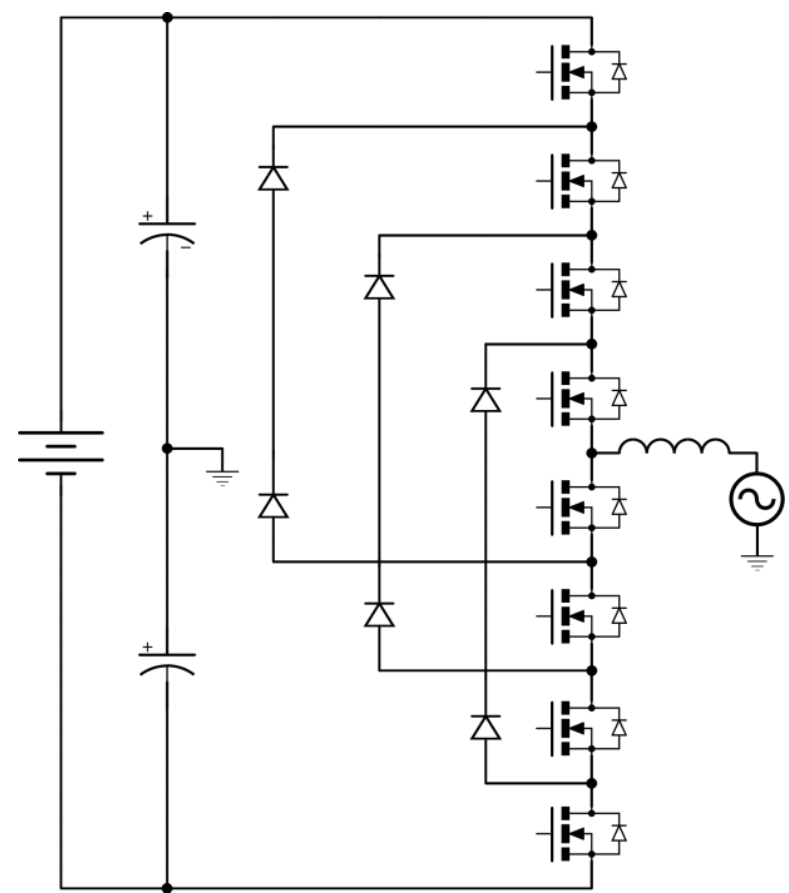

(a)

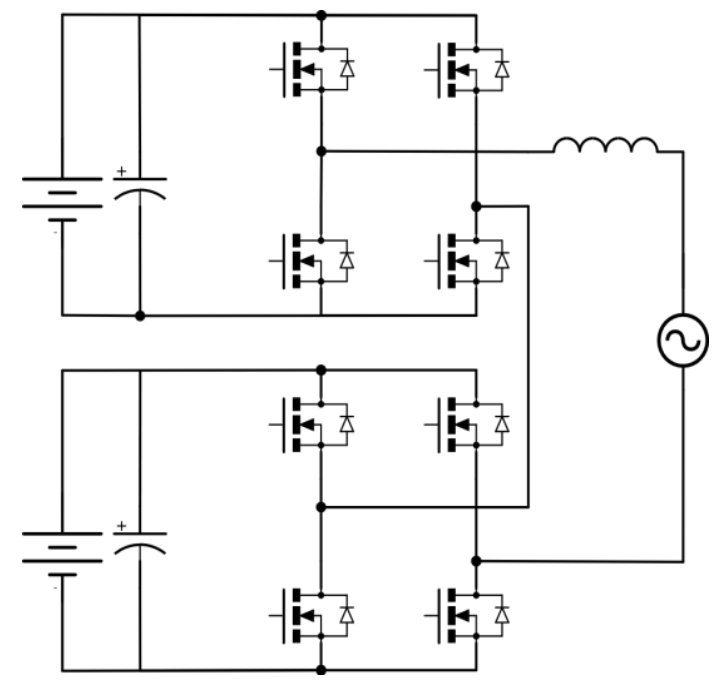

(b)

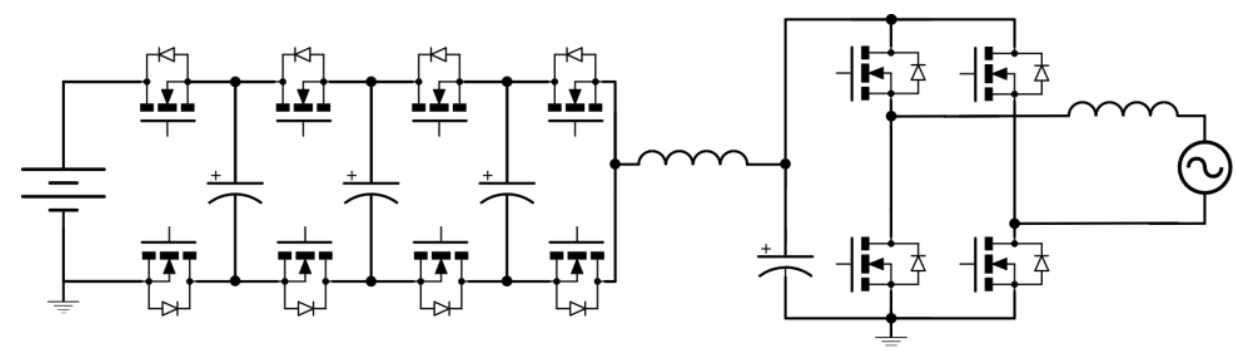

(c)

Figure 5. Examples of 5-level inverter topologies: (a) NPC; (b) CHB; (c) FC.

NPC converters (see Figure 5 (a)) are currently widely used in industrial applications in the range of $2.3 \mathrm{kV}$ to $4.16 \mathrm{kV}$ [26]. In particular, 3-level NPC converters are deployed as widely as possible [27-29]. In recent years, 4-level and 5-level NPC converters have been studied both to improve their power quality and increase their output power [30,31]. Nevertheless, 3-level NPC topologies have most times found industrial applications. The main drawback of a NPC topology is the difficulty to maintain the voltage balance between all DC capacitors. This issue has been solved through the development of new control strategies. However, such a strategy requires a significant computing power.

FC inverters (see Figure 5 (c)) are more commonly dedicated to high voltage and high power applications, because they allow a large serialization of power components [32]. Power semiconductor switches and diodes show some weaknesses in high voltage. The main challenge of FC inverters is to equally share the voltage between their various capacitors. The control strategy of this kind of multilevel converter must take into account the state of charge of all capacitors both to ensure a safe operation, and a high efficiency of the whole converter. However, in high power applications, FC topologies require large capacitor banks [33].

CHB inverters (see Figure 5 (b)) have been widely discussed in the literature because of many advantages such as simple layout (i.e., H-bridge), high modularity, and simple control strategy. Such 
a topology is a cascaded inverter which is composed of an addition of numerous converters connected in series. However, for PV power plants, the CHB topology exhibits a major drawback. Indeed, the power flow inside the power semiconductor switches is unbalanced, because of the electrical features of a PV module (i.e., the voltage and current from a solar panel are unbalanced too). All multilevel converters require the increase of the number of power devices to improve the output power quality. This necessarily has an impact on the compactness and the cost-effectiveness of the converter, but also on the control strategy complexity. Asymmetrical CHB topologies have been introduced to overcome those issues. Such a topology proposes to use unequal DC sources to reduce the number of power devices. This leads to an unequal power flow inside the various power switches, and unequal voltage stresses. Compared with NPC and FC topologies, CHB inverters require also many DC sources which must be isolated.

Table 1 sums up the main performances of such topologies reported in the literature [34-42]. The most important requirements stated in the previous section (i.e., efficiency higher than 95\%, and THD of the output signals lower than 5\%) can be achieved, and particularly with the NPC and FC topologies [34], [39]. Kadam et al. have particularly highlighted that 5-level NPC topology requires a high number of semiconductor devices (i.e., 8 power switches to be controlled, and 4 diodes), and a high number of mandatory capacitors (i.e., 4 capacitors) for the required function [34]. Regarding the FC topology, Lei et al. have highlighted that it is necessary to increase the number of levels (i.e., 7-level inverter structure), the number of semiconductor devices (i.e., 16 power switches to be controlled), and the number of mandatory capacitors (i.e., 6 capacitors) to meet the same performances as described above [39]. As a consequence, this solution increases the complexity of the converter. Some of the above issues can be partially covered by CHB topologies. Indeed, Villanueva et al. have proved that the THD-values of the output signals (i.e., either the current or the voltage) can reach approximately $5 \%$, without increasing the complexity of the topology (e.g., 8 semiconductor devices to be controlled) [40]. However, in this kind of 5-level inverter, the magnitude of the DC voltage is doubled in comparison with the NPC and FC topologies. Finally, in this example, the efficiency of the whole converter is not discussed. 


\section{New Bidirectional DC-AC Converter Topology Proposal}

\subsection{General Architecture}

Figure 6 shows the general architecture of the bidirectional DC-AC converter proposed in this article. Such a topology is based on the energy transfer between a DC voltage source and an AC one, and vice versa. The whole converter is composed of a DC-DC stage and a DC-AC stage which are in series.

The aim of the DC-DC stage is to generate a rectified sine wave. The inductance named $L$ (see Figure 6) is calculated to neglect the current ripple (which is the result of the high switching frequency i.e., $300 \mathrm{kHz}$ ) in comparison with the low-frequency signal component (i.e., $50 \mathrm{~Hz}$ ). So, the DC-DC converter is equivalent to a controllable output voltage source. The output current can be controlled by adjusting the voltage from an adaptive filtering stage. It has a major interest, and especially when the output current decreases drastically. In such cases, it is possible to decrease the $V c$-voltage. In particular, when the $V c$-parameter is higher than the $V a c$-one (i.e., the voltage from the AC mains), the output current has a positive value, and vice versa. Therefore, the electrical energy transfer is performed from the storage system to the AC-grid (inverter mode) or from the AC-grid to the storage system (rectifier mode). The DC-DC converter is composed of wide band-gap semiconductor devices, i.e. $36 \mathrm{~A}, 900 \mathrm{~V} \mathrm{SiC} \mathrm{MOSFETs} \mathrm{(C3M0065090D,} \mathrm{Cree).} \mathrm{Those} \mathrm{power} \mathrm{switches}$ enable, among other things, to increase the switching frequency to optimize the compactness of the whole converter.

The DC-AC stage is in charge of inverting a half sine wave out of two to get a full sine wave output signal. This stage is composed of four $47 \mathrm{~A}, 500 \mathrm{~V}$ MOSFETs (IRFPS43N50KPBF, Vishay). Their switching frequency is equal to $50 \mathrm{~Hz}$. This low frequency enables the use of MOSFETs manufactured on a silicon substrate. The power devices' turning-on and off are performed with zero-crossing of the AC mains to minimize the losses.

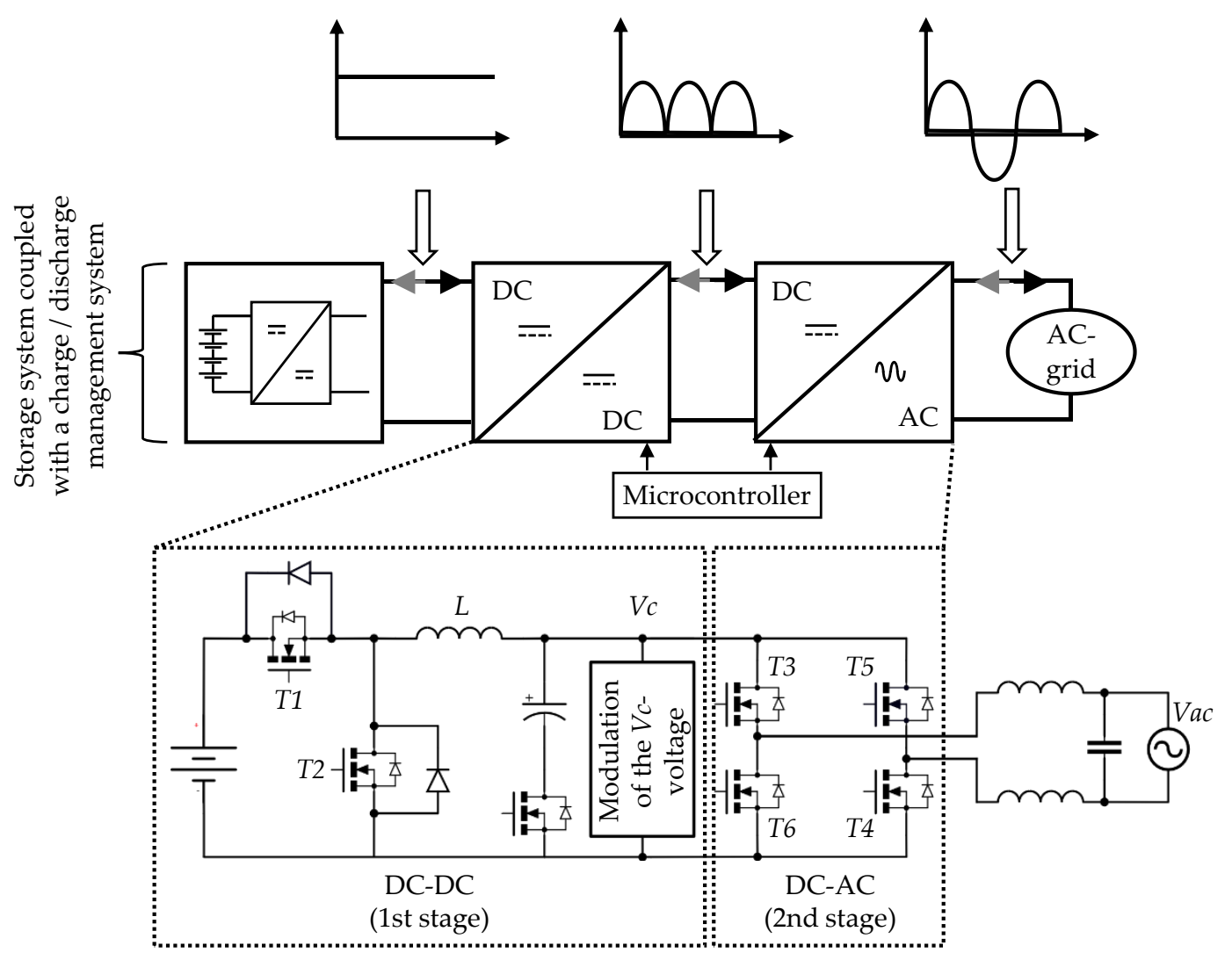

Figure 6. General schematic of the bidirectional DC-AC converter. 
The use of a DC-DC converter coupled with an H-bridge has many advantages comparing to existing topologies:

- Standard DC-DC converter and H-bridge are well-common topologies.

- Most of topologies use an H-bridge composed of at least four switches which operate at high frequency. In the topology described in this article, only two power devices (inside the first stage) operate at high frequency (i.e., $300 \mathrm{kHz}$ ). All the switches inside the H-bridge operate at low frequency (i.e., $50 \mathrm{~Hz}$ ).

- At high frequency, it is of utmost importance to take into consideration the delay between two switches in the same leg for safety reasons. With only one leg at high frequency, the safety delay is easier to control.

- At high frequency, the capacitance used to modulate the $V c$-voltage is low (about $13 \mu \mathrm{F}$ ). Many other topologies consider that the use of AC-type capacitor is mandatory.

\subsection{Solutions to Modulate the Output Voltage of the DC-DC stage}

As can be seen in Figure 7, three solutions are proposed to adjust the $V c$-voltage of the DC-DC stage. To explain each solution, the whole DC-AC converter is assumed to operate in the inverter mode.

The first solution (see Figure 7, Case 1) consists in using directly the capacitor (named C) of the DC-DC converter, which is equivalent here to a BUCK converter. Its capacitance must not be too low to avoid a high ripple on the $V c$-voltage. Even if this solution is simple because it does not use any power device, it has a major drawback. Indeed, a current may flow inside the transistor named T2 (see Figure 6) during the discharge of the capacitor named $C$. Thus, it can lead to overheating of the transistor.

To avoid the problem described above, as can be seen in Figure 7, Case 2, a resistor coupled with a switch can be used. If the impedance of the load is too high, then the capacitor named $C$ can be discharged through the resistor. It is important to note that this solution is useful when the output power of the inverter is not constant during its operation. However, this solution is particularly penalizing for the efficiency of the DC-DC stage and of course, the whole DC-AC converter.

The last solution (see Figure 7, Case 3) consists in $n$-quadrupoles in parallel. Each quadrupole is composed of a capacitor and a power switch which are in series. The aim of such a solution is to fix the ripple of the $V c$-voltage. In that case, there are $2^{n}-1$ possibilities to adjust the equivalent capacitance of the system. Even if this solution is slightly more complex than the previous ones, an adaptation to much more loads can be achieved. Finally, the efficiency of the DC-DC stage is not so much penalized in that case. In the next sections of the manuscript, three capacitances were used.

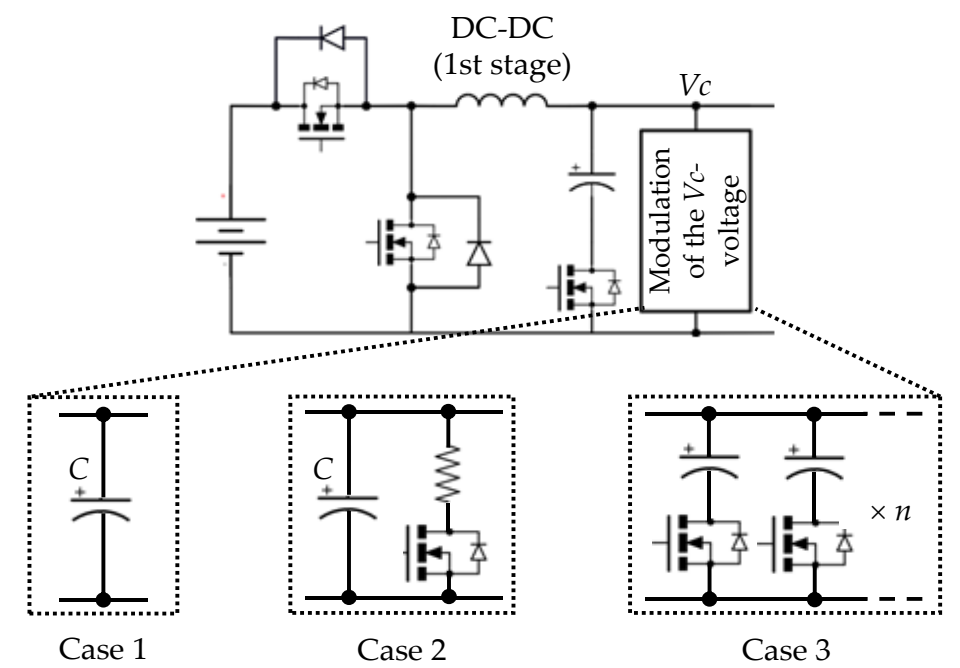

Figure 7. Solutions to modulate the output voltage of the DC-DC stage. 


\subsection{Control strategies}

\subsubsection{Inverter Mode}

In the inverter mode, the power flows from the storage system to the AC-grid. In this kind of operation, the most important objective is to control the current injected to the AC-grid by adjusting the output voltage of the DC-DC stage. In that case, the modulation of this output voltage is performed using three quadrupoles in parallel (see Figure 7, Case 3). The values of the three capacitances are equal to $10 \mu \mathrm{F}, 1 \mu \mathrm{F}$, and $68 \mathrm{nF}$, respectively. It is important to remind that the values of those capacitances must be well-designed to minimize the ripple of the $V c$-voltage. As can be seen in Figure 8, when the value of the capacitance is low or high, the THD-values of the output signals increase.

Figure 9 shows the structure of the control circuit of the MOSFETs inside the first stage. This stage is in charge of generating a half sine output signal. To achieve this objective, the microcontroller adjusts the duty cycle of each power device. The higher the duty cycle, the higher the injected current on the AC-grid.

Grid current
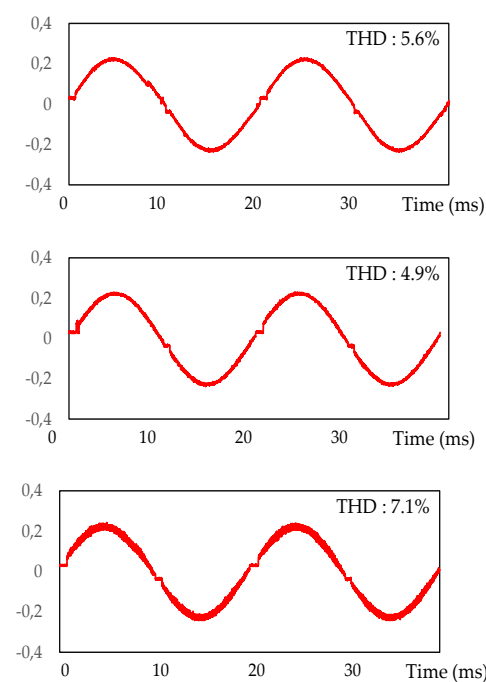

Grid voltage
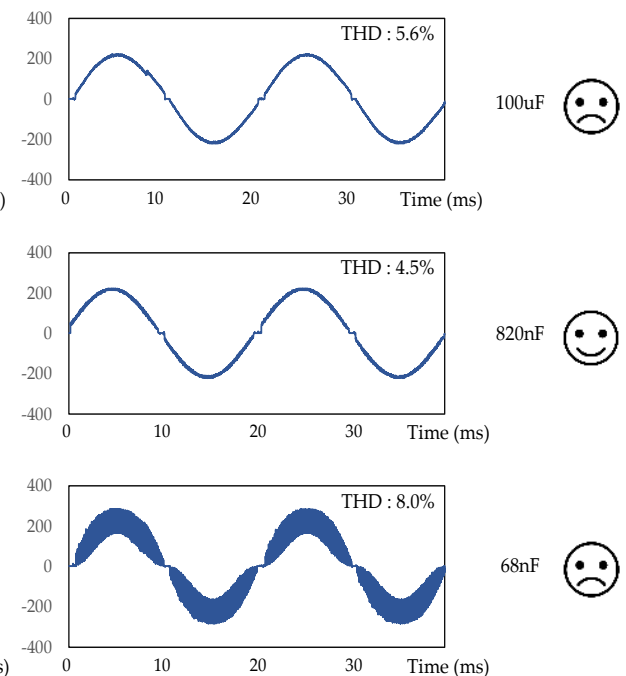

Figure 8. Effects of the capacitors on the output voltage of the inverter.

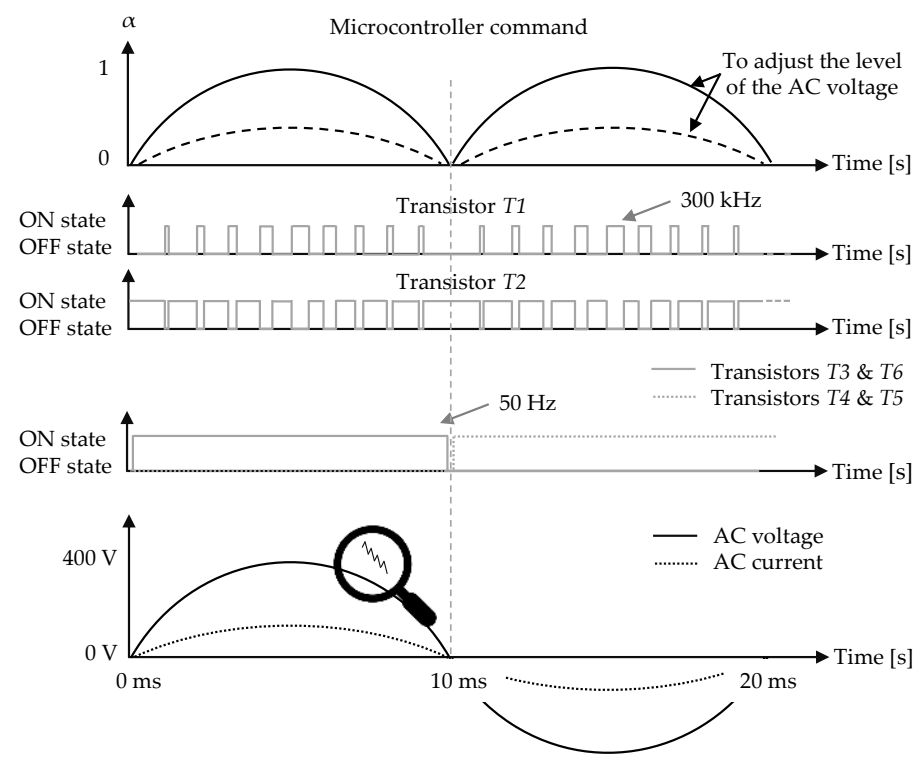

Figure 9. Control strategy of the MOSFETs inside the bidirectional DC-AC converter in the inverter mode. 


\subsubsection{Rectifier Mode}

In the rectifier mode, the power flows from the AC-grid to the storage system. In this kind of operation, the most important objective is to control the absorbed current. This one must have a sinusoidal waveform. As a consequence, a power factor correction (PFC) is mandatory to be compliant with the IEC 61000-3-2 standard. This function is performed thanks to the DC-DC stage.

As can be seen in Figure 10, it is also important to modulate the $V c$-parameter by adjusting the equivalent capacitance (see Figure 7, Case 3). In particular, this capacitance must be optimized (about $800 \mathrm{nF}$ ) to be sure that the absorbed current is quasi sinusoidal.

Figure 11 shows the structure of the control circuit of the MOSFETs inside the DC-DC stage. The control circuit is composed of a current sensor and a voltage sensor which enable to create the PFC strategy.
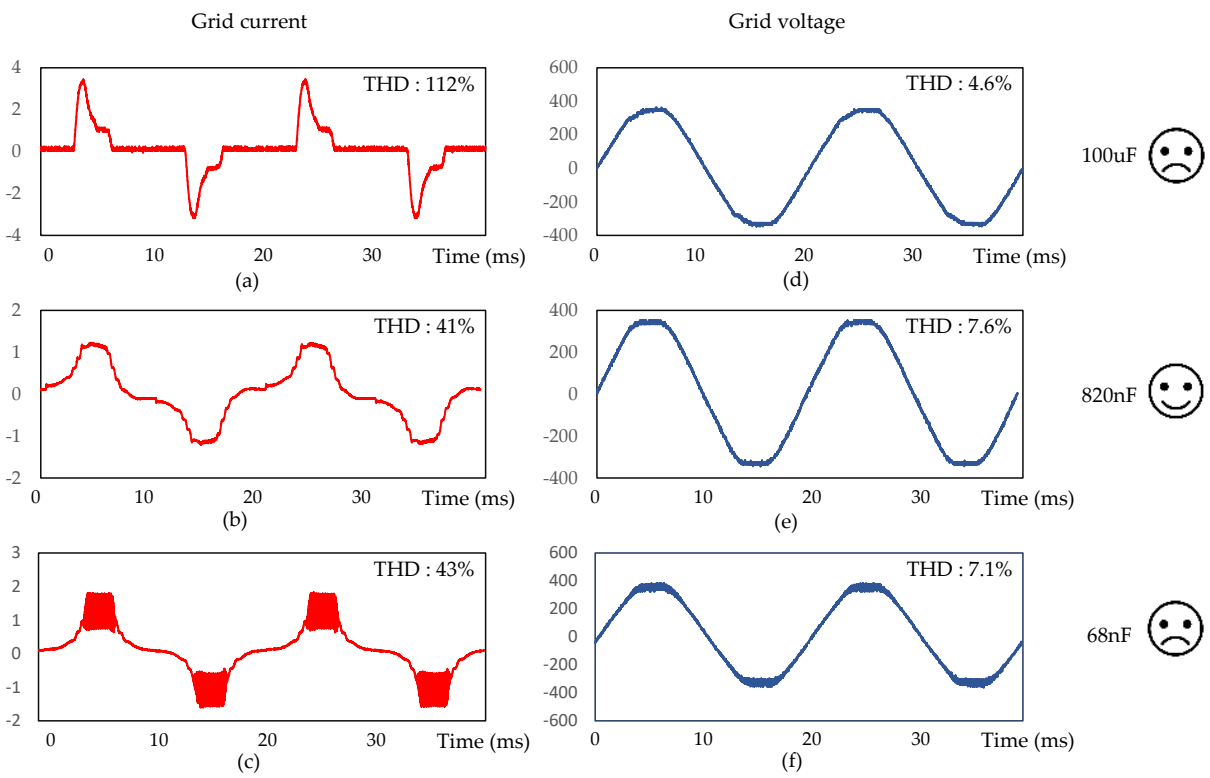

Figure 10. Effects of the capacitors on the absorbed current (AC-grid).
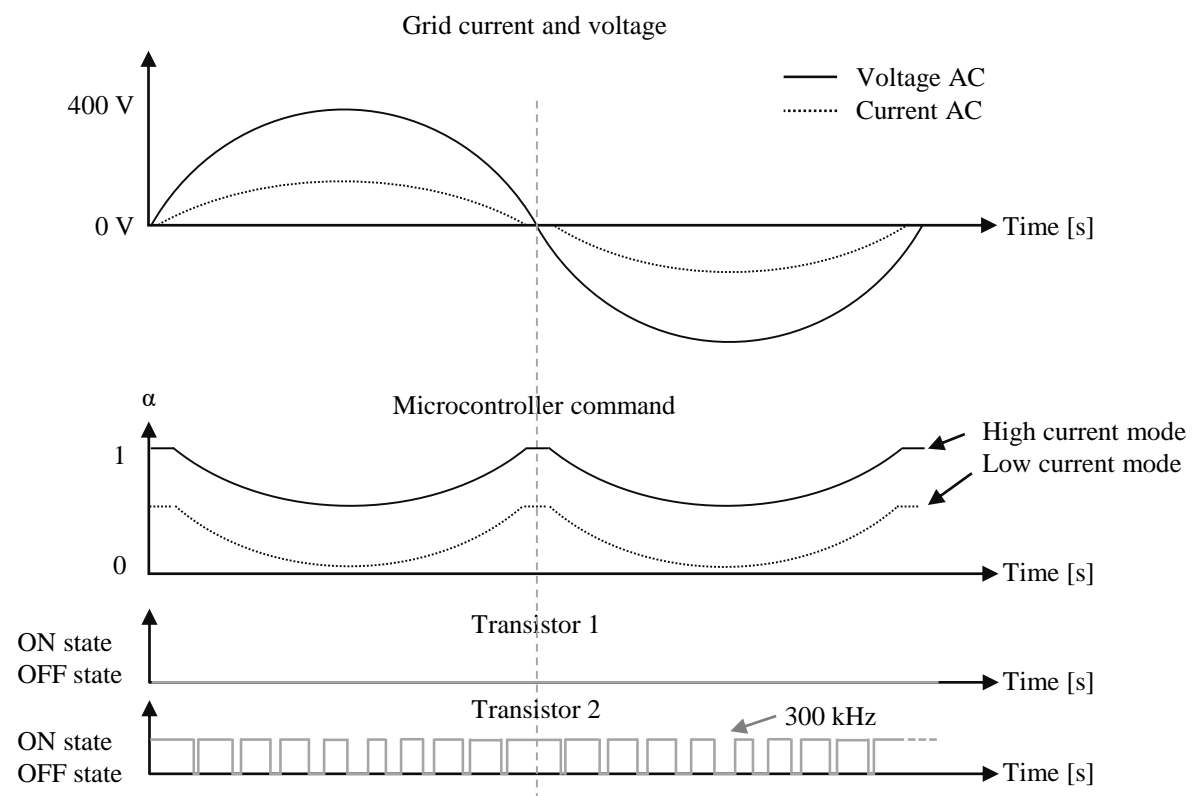

Figure 11. Control strategy of the MOSFETs inside the bidirectional DC-AC converter in the rectifier mode. 


\section{Experimental Validation: Main Results and Discussion}

\subsection{Experimental Test Setup}

The operation modes of the bidirectional DC-AC converter described in this manuscript were validated at low power (i.e., lower than $1.5 \mathrm{~kW}$ ) through a complete experimental test procedure. Figure 12 gives the illustration of the whole converter. This one is composed of a DC-DC stage, a DC-AC stage, an adaptive filter, and a power supply (i.e., $+5 \mathrm{~V}$, and $+12 \mathrm{~V}$ ) to supply the onboard electronics. The whole converter is powered by a STM32F407VG microcontroller. A $3 \mathrm{~kW}$ programmable DC power supply (reference: SM300-10, Delta Electronika) was used to simulate the storage system (i.e., the DC input). This kind of power supply has two independent outputs (i.e., each channel can be adjustable from 0 to $300 \mathrm{~V}$ for the voltage, and from 0 to $10 \mathrm{~A}$ for the current). A resistive load (1,300 W rheostat; from 0 to $11.5 \Omega ; 10 \mathrm{~A}$; reference: ECO2-106, Langlois) was used in the DC-AC stage to be sure that its main principle of operation was well contained. Of course, in the near future, the final prototype of the whole system will be tested using non-linear loads.

A high voltage differential probe (reference: P5205, Tektronix), and a 15 A AC/DC current probe (reference: TCP202, Tektronix) were used to measure the output voltage and output current, respectively. The output power of the DC-DC stage was measured using a watt meter (reference: PX 110, Metrix). Regarding the measurement of the output power of the DC-AC stage, the same type of electronic meter was used. Finally, the THD of the output voltage (or current) of the inverter was measured using a clamp-on harmonic power meter (reference: F27, Chauvin Arnoux). This kind of power meter can measure a THD-value up to the rank no. 25, with frequencies between $0.5 \mathrm{~Hz}$ and $20 \mathrm{kHz}$.

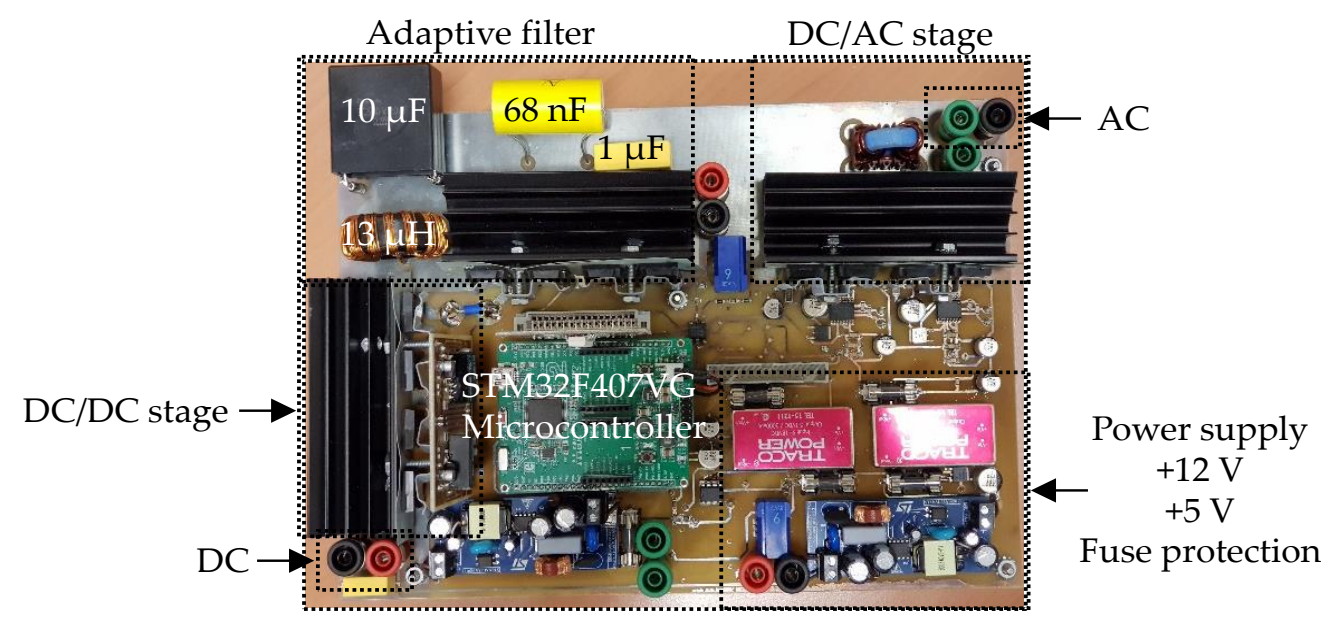

Figure 12. Prototype of the proposed bidirectional DC-AC converter.

\subsection{Experimental Validation of the Operation Modes of the Bidirectionnal DC-AC Converter}

\subsubsection{Inverter Mode}

In this section of the manuscript, the aim is to validate the operation of the bidirectional DC-AC converter in the inverter mode. The experimental tests were performed in the following conditions:

- Input voltage (i.e., DC voltage): $300 \mathrm{~V}$.

- Output voltage (i.e., AC voltage): 170 V RMS.

- Output power: $600 \mathrm{~W}$.

Figure 13 shows the output signals of the inverter. In this mode, the converter generates quasi sinewave signals. It is important to note that the inverter was not connected to the AC grid. The resistive load used in this experimental procedure was slightly inductive (i.e., about $360 \mu \mathrm{H}$ and $285 \mu \mathrm{H}$ at $120 \mathrm{~Hz}$ and $1 \mathrm{kHz}$, respectively). Thus, the current through the load is smoothed. Figure 14 shows the harmonic spectra at $50 \mathrm{~Hz}$ and $50 \mathrm{kHz}$ of the output signals, either the current 
(see Figure 14 (a) and Figure 14 (b)) or the voltage (Figure 14 (c) and Figure 14 (d)). The main contribution of each spectral decomposition is due to the fundamental, because of the quasi sinewave signals. The harmonics are reduced, whatever the output signal. In the experimental conditions described above, the THD-values of the output signals are about $5 \%$. In comparison with a 5-level topology described in the literature (THD-value about 37\%), under approximately the same experimental conditions, the THD-value is here very low [18]. As a consequence, the topology proposed in this article is validated in the inverter mode.

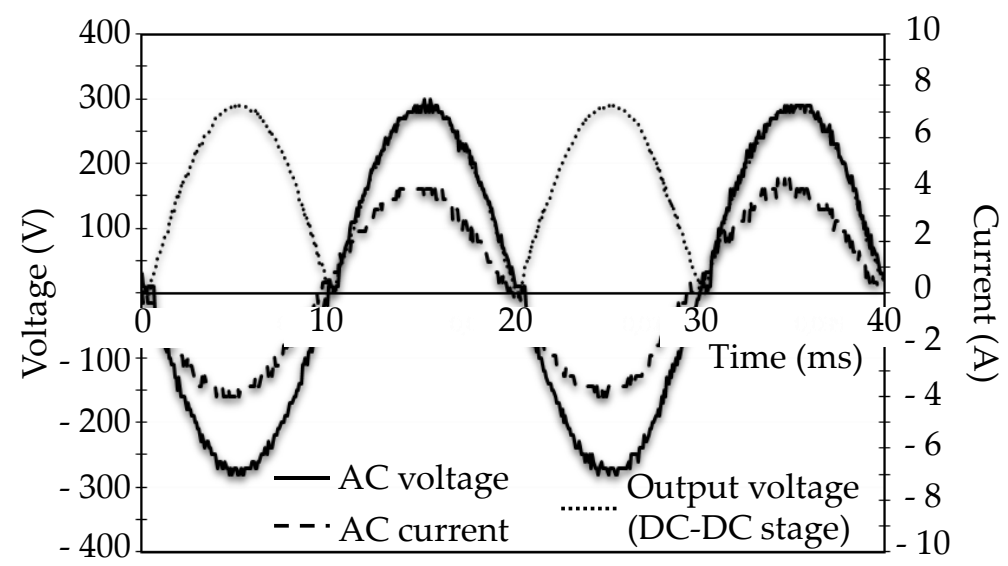

Figure 13. Validation of the inverter mode: output signals.

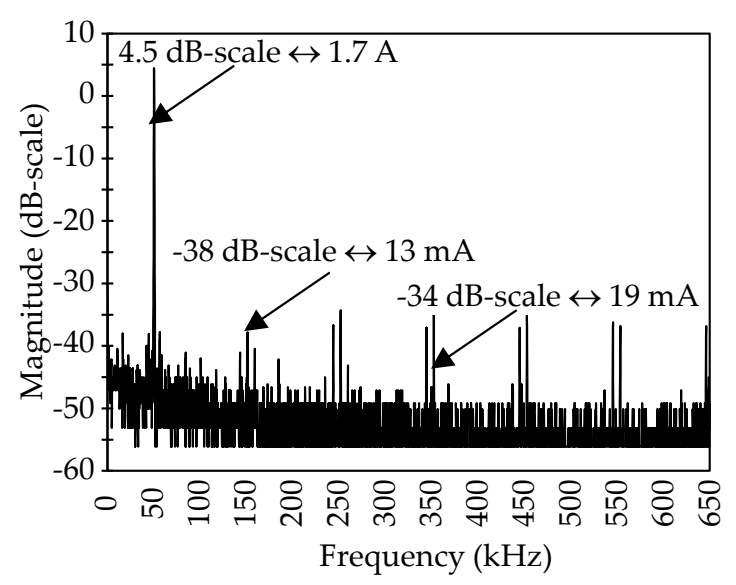

(a)

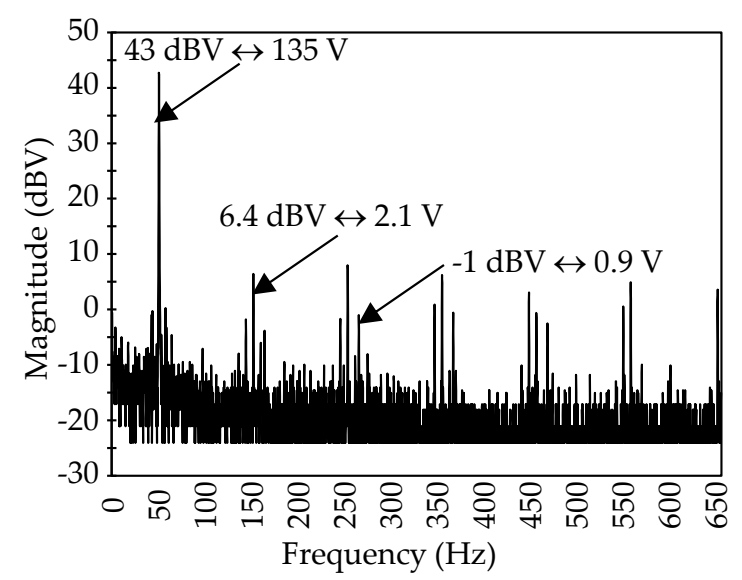

(c)

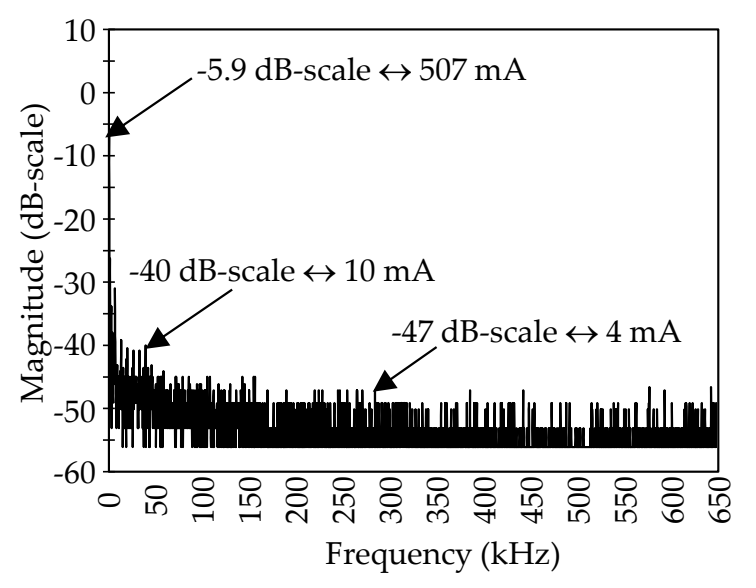

(b)

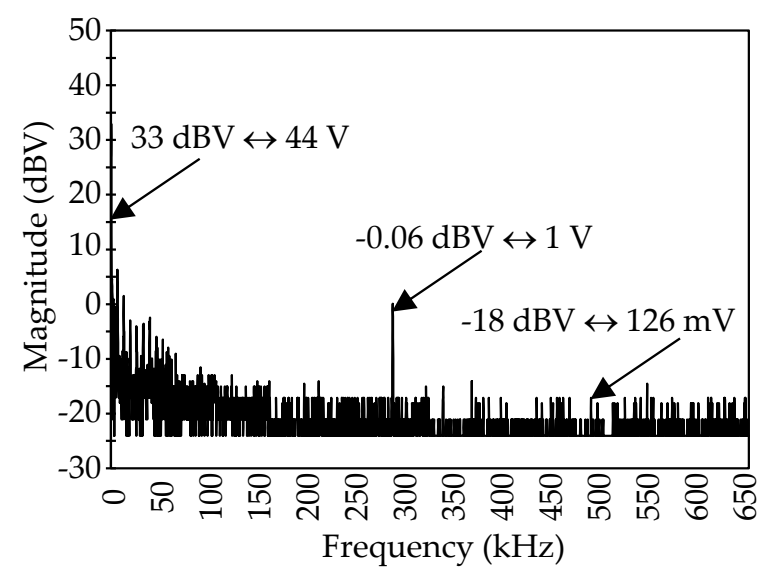

(d)

Figure 14. Harmonic spectra of the output signals (inverter mode): (a) Output current at $50 \mathrm{~Hz}$; (b) Output current at $50 \mathrm{kHz}$; (c) Output voltage at $50 \mathrm{~Hz}$; (d) Output voltage at $50 \mathrm{kHz}$. 


\subsubsection{Rectifier Mode}

In this section of the manuscript, the aim is to validate the operation of the bidirectional DC-AC converter in the rectifier mode. Above all, the aim was to prove the feasibility to create a power factor correction (PFC). Specifically, the sinusoidal current absorption was carried out thanks to the control of the transistor named T2 (see Figure 6) of the DC-DC stage. The experimental tests were also performed at low power to avoid deteriorating the prototype of the whole converter.

Figure 15 highlights the effective operation of the rectifier in the following conditions:

- Input voltage (i.e., AC voltage): $100 \mathrm{~V}$ (peak value).

- Output voltage (i.e., DC voltage): $300 \mathrm{~V}$.

- Output power: $120 \mathrm{~W}$.

Figure 16 shows the harmonic spectrum of the output current. In particular, these results exhibit the benefits of a sinusoidal current absorption on the magnitude of the harmonics.

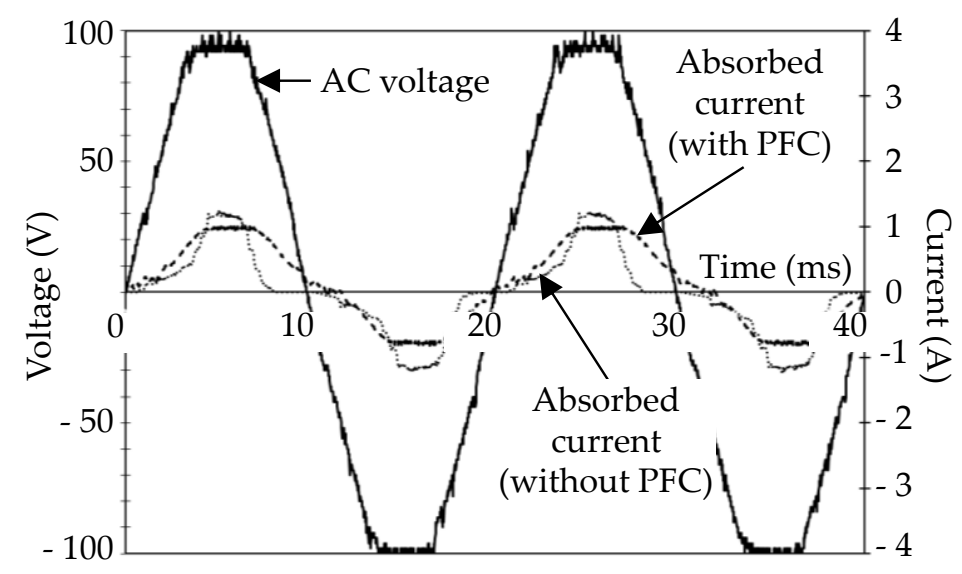

Figure 15. Validation of the rectifier mode with a sinusoidal current absorption.

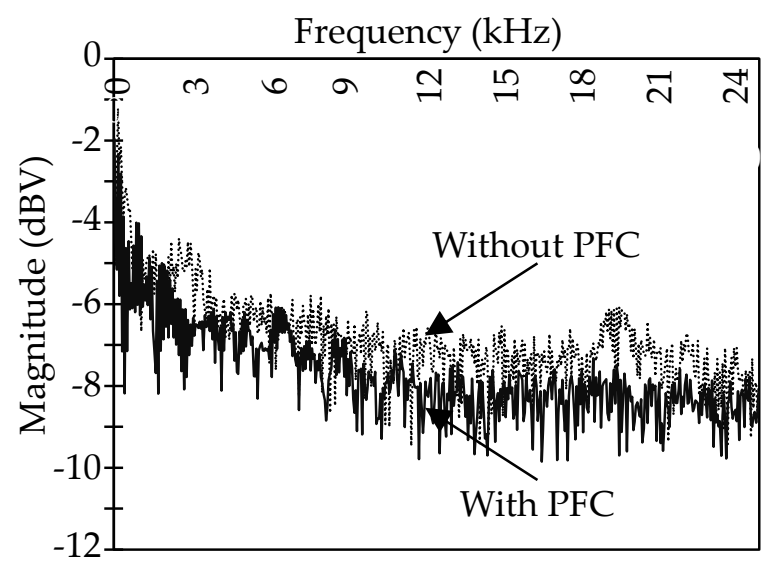

Figure 16. Harmonic spectrum of the output current (rectifier mode).

\subsection{Efficiency of the Bidirectional DC-AC Converter}

Figure 17 shows the evolution of the efficiency of the bidirectional DC-AC converter depending on the output power.

Regarding the inverter mode (see Figure 17 (a)), the measurements were performed up to $1,300 \mathrm{~W}$. The experimental results exhibit that the efficiency of the inverter can reach $96 \%$. It must be noted that these results depend on the overall topology of the DC-AC converter. Even if the efficiency of the DC-DC stage is very good (i.e., about 98.5\%), it would be difficult to improve the efficiency of the overall DC-AC converter, because this topology is composed of two stages in series. 
Nonetheless, these experimental results are very encouraging, particularly for one third of the targeted value of the output power.

Regarding the rectifier mode (see Figure $17(b)$ ), the measurements were performed up to $500 \mathrm{~W}$. The experimental results are very satisfactory, because the efficiency of the rectifier can reach $95.5 \%$ at low power.

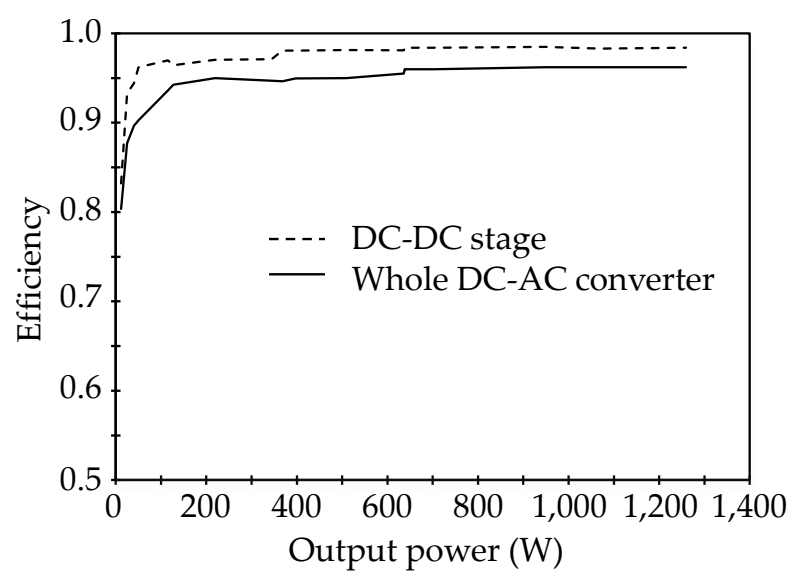

(a)

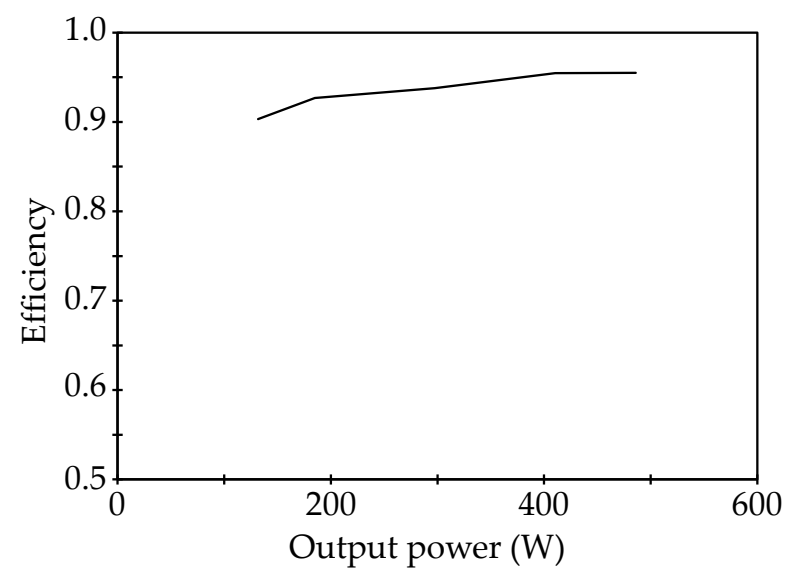

(b)

Figure 17. Efficiency of the bidirectional DC-AC converter: (a) Inverter mode; (b) Rectifier mode.

\section{Conclusions}

This article proposed an innovative bidirectional DC-AC converter that can operate in HEMS, particularly when an electrical energy transfer is required between a storage system and the AC-grid, and vice versa. The proposed topology is based on two stages, a DC-DC stage (composed of $\mathrm{SiC}$ power MOSFETs that are controlled at $300 \mathrm{kHz}$ ) and a DC-AC one (an H-bridge composed of silicon MOSFETs that are controlled at $50 \mathrm{~Hz}$ ), which are in series. The aim is to generate sine half-waves to optimize the power quality of the whole converter. Such a topology was tested through a complete experimental procedure.

The main achievements of this study are summed up below:

1. The complexity of the topology is minimized in comparison with existing multilevel converters.

2. The THD-values of the output signals (either the current or the voltage) are about $5 \%$ whatever the operation mode of the DC-AC converter (i.e., inverter or rectifier).

3. The efficiency of the bidirectional converter is slightly higher than $95 \%$.

4. The compactness of the whole system is minimized, in particular through the use of wide band-gap semiconductor devices. 
In this article, a first prototype of the bidirectional DC-AC converter was designed and tested at low power (i.e., lower than $1.5 \mathrm{~kW}$ ). Moreover, the whole system was not connected to the AC-grid. It will be interesting to test a grid-connected prototype of the converter. Finally, its operating modes will have to be validated for its targeted nominal power (i.e., $3 \mathrm{~kW}$ ).

Author Contributions: Sébastien Jacques, Cédric Reymond and Jean-Charles Le Bunetel organized and refined the manuscript.

Sébastien Bissey conducted all the experiments and co-authored the article.

Acknowledgments: These research activities are currently supported by "Région Centre Val-de-Loire" (research project number: 2015-00099656). The authors of this manuscript thank our colleagues from this institution who provided insight and expertise that greatly assisted the project.

Conflicts of Interest: The authors declare no conflict of interest.

\section{Abbreviations}

The following abbreviations are used in this manuscript:

$\begin{array}{ll}\text { AC } & \text { Alternating current } \\ \text { CHB } & \text { Cascaded H-bridge } \\ \text { DC } & \text { Direct current } \\ \text { FC } & \text { Flying capacitor } \\ \text { HEMS } & \text { Home electricity management systems } \\ \text { MOSFET } & \text { Metal oxide semiconductor field effect transistor } \\ \text { NPC } & \text { Neutral point clamped } \\ \text { PFC } & \text { Power factor correction } \\ \text { PV } & \text { Photovoltaics } \\ \text { SiC } & \text { Silicon carbide } \\ \text { THD } & \text { Total harmonic distortion }\end{array}$

\section{References}

1. Torriti, J. The Risk of Residential Peak Electricity Demand: A Comparison of Five European Countries. Energies 2017, 10(3), 385, doi: 10.3390/en10030385.

2. Zheng, W.; Wu, W.; Zhang, B.; Lin, C. Distributed optimal residential demand response considering operational constraints of unbalanced distribution networks. IET Generation, Transmission and Distribution 2018, 12(9), 1970-1979, doi: 10.1049/iet-gtd.2017.1366.

3. Jiang, Y.; Liu, C.-C.; Xu, Y. Smart Distribution Systems. Energies 2016, 9(4), 297, doi: 10.3390/en9040297.

4. Andreadou, N.; Kotsakis, E.; Masera, M. Smart Meter Traffic in a Real LV Distribution Network. Energies 2018, 11(5), 1156, doi: 10.3390/en11051156.

5. Lu, H. H.-C.; Chu, C.-C.; Nwankpa, C. O.; Wu, C. W. Guest Editorial Complex Network for Modern Smart Grid Application-Part 2: Stability, Reliability and Resilience Issues. IEEE Journal on Emerging and Selected Topics in Circuits and Systems 2017, 7(3), 345-348, doi: 10.1109/JETCAS.2017.2723698.

6. Iqbal, Z.; Javaid, N.; Iqbal, S.; Aslam, S.; Ali Khan, Z.; Abdul, W.; Almogren, A.; Alamri, A. A Domestic Microgrid with Optimized Home Energy Management System. Energies 2018, 11(4), 1002, doi: 10.3390/en11041002.

7. Kim, Y.-S.; Hwang, C.-S.; Kim, E.-S.; Cho, C. State of Charge-Based Active Power Sharing Method in a Standalone Microgrid with High Penetration Level of Renewable Energy Sources. Energies 2016, 9(7), 480, doi: 10.3390/en9070480.

8. Khan, S.; Khan, R. Elgamal Elliptic Curve Based Secure Communication Architecture for Microgrids. Energies 2018, 11(4), 759, doi: 10.3390/en11040759.

9. Sreekumar, P.; Khadkikar, V. Adaptive Power Management Strategy for Effective Volt-Ampere Utilization of a Photovoltaic Generation Unit in Standalone Microgrids. IEEE Transactions on Industry Applications 2018, 54(2), 1784-1792, doi: 10.1109/TIA.2017.2781643.

10. Yang, J.; Liu, J.; Fang, Z.; Liu, W. Electricity scheduling strategy for home energy management system with renewable energy and battery storage: a case study. IET Renewable Power Generation 2018, 12(6), 639-648, doi: 10.1049/iet-rpg.2017.0330. 
11. Bissey, S.; Jacques, S.; Le Bunetel, J.-C. The Fuzzy Logic Method to Efficiently Optimize Electricity Consumption in Individual Housing. Energies 2017, 10(11), 1701, doi: 10.3390/en10111701.

12. Esther, B. P.; Kumar, K. S. A survey on residential Demand Side Management architecture, approaches, optimization models and methods. Renew. Sustain. Energy Rev. 2016, 59, 342-351, doi: 10.1016/j.rser.2015.12.282.

13. Sayed, M. A.; Suzuki, K.; Takeshita, T.; Kitagawa, W. Soft-Switching PWM Technique for Grid-Tie Isolated Bidirectional DC-AC Converter With SiC Device. IEEE Transactions on Industry Applications. 2017, 53(6), 5602-5614, doi: 10.1109/TIA.2017.2731738.

14. Jin, P.; Li, Y.; Li, G.; Chen, Z.; Zhai, X. Optimized hierarchical power oscillations control for distributed generation under unbalanced conditions. Appl. Energy 2017, 194, 343-352, doi: 10.1016/J.APENERGY.2016.06.075.

15. Prieto Thomas, J.; Salmerón Revuelta, P.; Pérez Vallés, A.; Pérez Litrán, S. Practical evaluation of unbalance and harmonic distortion in power conditioning. Electr. Power Syst. Res. 2016, 141, 487-499, doi: 10.1016/J.EPSR.2016.08.012.

16. Sannino, A.; Bollen, M. H. J.; Svensson, J. Voltage Tolerance Testing of Three-Phase Voltage Source Converters. IEEE Trans. Power Deliv. 2005, 20, 1633-1639, doi: 10.1109/TPWRD.2004.833881.

17. Nabae, A.; Takahashi, I.; Akagi, H. A New Neutral-Point-Clamped PWM Inverter. IEEE Trans. Ind. Appl. 1981, IA-17, 518-523, doi: 10.1109/TIA.1981.4503992.

18. Jacques, S.; Caldeira, A.; Schellmanns, A.; Ren, Z.; Batut, N. New Multilevel Mixed Topology Development to Improve Inverter Robustness for Domestic Photovoltaic Installations. Journal of Power and Energy Engineering 2013, 1(5), 1-6, doi: 10.4236/jpee.2013.15001.

19. Babaei, E.; Laali, S.; Bayat, Z. A Single-Phase Cascaded Multilevel Inverter Based on a New Basic Unit With Reduced Number of Power Switches. IEEE Trans. Ind. Electron. 2015, 62, 922-929, doi: 10.1109/TIE.2014.2336601

20. Seth, N.; Goel, V.; Kulkarni, R. D.; Joshi, V. P. Performance analysis of seven level three phase asymmetric multilevel Inverter at various modulation indices. In 2016 International Conference on Electrical Power and Energy Systems (ICEPES); IEEE, 2016; pp. 407-413.

21. Gupta, K. K.; Ranjan, A.; Bhatnagar, P.; Sahu, L. K.; Jain, S. Multilevel Inverter Topologies With Reduced Device Count: A Review. IEEE Trans. Power Electron. 2016, 31, 135-151, doi: 10.1109/TPEL.2015.2405012.

22. Meynard, T. A.; Foch, H. Multi-level conversion: high voltage choppers and voltage-source inverters. In PESC '92 Record. 23rd Annual IEEE Power Electronics Specialists Conference; IEEE; pp. 397-403.

23. Zaohong Yang Bidirectional DC-to-AC inverter with improved performance. IEEE Trans. Aerosp. Electron. Syst. 1999, 35, 533-542, doi: 10.1109/7.766935.

24. Koutroulis, E.; Chatzakis, J.; Kalaitzakis, K.; Voulgaris, N. C. A bidirectional, sinusoidal, high-frequency inverter design. IEE Proc. - Electr. Power Appl. 2001, 148, 315, doi: 10.1049/ip-epa:20010351.

25. Karimi, M.; Jannati Oskuee, M. R.; Ravadanegh, S. N.; Gharehpetian, G. B. A developed single-phase cascaded multilevel inverter with reduced number of circuit devices. Int. J. Ambient Energy 2017, 1-9, doi: 10.1080/01430750.2017.1372812.

26. Rodriguez, J.; Bernet, S.; Steimer, P. K.; Lizama, I. E. A Survey on Neutral-Point-Clamped Inverters. IEEE Trans. Ind. Electron. 2010, 57, 2219-2230, doi: 10.1109/TIE.2009.2032430

27. Wang, Y.; Xu, Q.; Ma, Z.; Zhu, H. An Improved Control and Energy Management Strategy of Three-Level NPC Converter Based DC Distribution Network. Energies 2017, 10, 1635, doi: 10.3390/en10101635.

28. Bennani-Ben Abdelghani, A.; Ben Abdelghani, H.; Richardeau, F.; Blaquiere, J.-M.; Mosser, F.; Slama-Belkhodja, I. Versatile Three-Level FC-NPC Converter With High Fault-Tolerance Capabilities: Switch Fault Detection and Isolation and Safe Postfault Operation. IEEE Trans. Ind. Electron. 2017, 64, 6453-6464, doi: 10.1109/TIE.2017.2682009.

29. Andrade, A. S.; Maciel, A. M.; Barros, L. de M.; Vieira, M. A. do N.; de Sousa, R. P. R. A control technique to balance the voltage of DC-link for three-level NPC converter. In 2017 Brazilian Power Electronics Conference (COBEP); IEEE, 2017; pp. 1-6.

30. Chaves, M.; Silva, J.; Pinto, S.; Margato, E.; Santana, J. A New Backward Euler Stabilized Optimum Controller for NPC Back-to-Back Five Level Converters. Energies 2017, 10, 735, doi: 10.3390/en10060735.

31. Neto, J. A. F.; Bascope, R. P. T.; Cacau, R. G. A. A five-level stacked neutral point clamped converter based on multi-state switching cell. In 2017 Brazilian Power Electronics Conference (COBEP); IEEE, 2017; pp. 1-6. 
32. Meynard, T. A.; Foch, H.; Thomas, P.; Courault, J.; Jakob, R.; Nahrstaedt, M. Multicell converters: basic concepts and industry applications. IEEE Trans. Ind. Electron. 2002, 49, 955-964, doi: 10.1109/TIE.2002.803174.

33. Adam, G. P.; Anaya-Lara, O.; Burt, G.; Mcdonald, J. R. Comparison between flying capacitor and modular multilevel inverter. In IECON 2009. 35th Annual Conference of the IEEE Industrial Electronics Society; IEEE.

34. Kadam, A.; Shukla, A. A 5-level high efficiency low cost Hybrid Neutral Point Clamped transformerless inverter for grid connected photovoltaic application. In 2018 IEEE Applied Power Electronics Conference and Exposition (APEC); IEEE, 2018; pp. 3189-3194.

35. Duman, T.; Marti, S.; Moonem, M.; Kader, A. A.; Krishnaswami, H. A Modular Multilevel Converter with Power Mismatch Control for Grid-Connected Photovoltaic Systems. Energies 2017, 10, 698, doi: 10.3390/en10050698.

36. Kang, J.-W.; Lee, H.; Hyun, S.-W.; Kim, J.; Won, C.-Y. An Enhanced Control Scheme Based on New Adaptive Filters for Cascaded NPC/H-Bridge System. Energies 2018, 11, 1034, doi: 10.3390/en11051034.

37. Chang-xin, M.; Li-ping, S.; Tai-xu, W.; Cheng-bao, C. Flying capacitor multilevel inverters with novel PWM method. Procedia Earth Planet. Sci. 2009, 1, 1554-1560, doi:10.1016/J.PROEPS.2009.09.240.

38. Feng, C.; Liang, J.; Agelidis, V. G. Modified Phase-Shifted PWM Control for Flying Capacitor Multilevel Converters. IEEE Trans. Power Electron. 2007, 22, 178-185, doi:10.1109/TPEL.2006.886600.

39. Lei, Y.; Barth, C.; Qin, S.; Liu, W.-C.; Moon, I.; Stillwell, A.; Chou, D.; Foulkes, T.; Ye, Z.; Liao, Z.; Pilawa-Podgurski, R. C. N. A 2-kW Single-Phase Seven-Level Flying Capacitor Multilevel Inverter With an Active Energy Buffer. IEEE Trans. Power Electron. 2017, 32, 8570-8581, doi:10.1109/TPEL.2017.2650140.

40. Villanueva, E.; Correa, P.; Rodriguez, J.; Pacas, M. Control of a Single-Phase Cascaded H-Bridge Multilevel Inverter for Grid-Connected Photovoltaic Systems. IEEE Trans. Ind. Electron. 2009, 56, 4399-4406, doi:10.1109/TIE.2009.2029579.

41. Xiao, B.; Filho, F.; Tolbert, L. M. Single-phase cascaded H-bridge multilevel inverter with nonactive power compensation for grid-connected photovoltaic generators. In 2011 IEEE Energy Conversion Congress and Exposition; IEEE, 2011; pp. 2733-2737.

42. Hinago, Y.; Koizumi, H. A Single-Phase Multilevel Inverter Using Switched Series/Parallel DC Voltage Sources. IEEE Trans. Ind. Electron. 2010, 57, 2643-2650, doi:10.1109/TIE.2009.2030204. 